\title{
REVISTA
}

IIt:़̣:C|ênc|a

\section{DAS RECENTES CRISES ECONÔMICAS À CRISE DA COVID-19: REFLEXÕES E PROPOSIÇÕES PARA O ENFRENTAMENTO DA PANDEMIA NA ECONOMIA BRASILEIRA E CAPIXABA}

\author{
FROM RECENT ECONOMIC CRISES TO THE CRISIS OF COVID-19: REFLECTIONS \\ AND PROPOSITIONS FOR FACING THE PANDEMIC COVID-19 IN THE BRAZILIAN \\ ECONOMY AND THE ECONOMY OF THE ESPIRITO SANTO
}

\begin{abstract}
${ }^{1}$ Celso Bissoli Sessa
${ }^{2}$ Daniel Farinelli Leite

${ }^{3}$ Ednilson Silva Felipe ${ }^{4}$ Érika de Andrade Silva Leal ${ }^{5}$ Luiz Henrique Lima Faria

${ }^{6}$ Rafael Buback Teixeira

${ }^{7}$ Rodrigo Loureiro Medeiros

${ }^{1}$ Universidade Federal do Espírito Santo. E-mail: celso.bissoli@gmail.com. ${ }^{2}$ Instituto Federal do Espírito Santo/Campus Cariacica. E-mail: Daniel.leite@ifes.edu.br. ${ }^{3}$ Universidade Federal do Espírito Santo. E-mail: ednilsonfelipe.ufes@gmail.com. ${ }^{4}$ Instituto Federal do Espírito Santo/ Campus Cariacica. E-mail:professoraerikaleal@gmail.com.

${ }^{5}$ Instituto Federal do Espírito Santo/ Campus Cariacica. E-mail: luizlima@ifes.edu.br. ${ }^{6}$ Instituto Federal do Espírito Santo/ Campus Cariacica. E-mail: Rafael.teixieira@ifes.edu.br.

${ }^{7}$ Instituto Federal do Espírito Santo/ Campus Cariacica. E-mail: medrodrigo@gmail.com.
\end{abstract}

*Autora de correspondência: Érika de Andrade Silva Leal

Artigo submetido em 05/05/2020, aceito em 01/06/2020 e publicado em 15/06/2020.

Resumo: Em face da grave crise que se instalou em todo o mundo, dada a chegada da pandemia Covid-19, quase todos os países têm adotado medidas de enfrentamento ao coronavírus, basicamente, usando estratégias de distanciamento social. Essas propostas têm afetado diretamente a atividade econômica e a preocupação com os efeitos negativos principalmente sobre a renda do trabalhador e o emprego, suscitando dos governos a adoção medidas para mitigar os efeitos da paralisação das atividades como a indústria, o comércio, os serviços e a agricultura. No entanto, ainda é cedo para afirmar sobre a efetividade dessas decisões, porque a construção de cenários quanto ao comportamento da economia, mesmo no curto prazo, se tornou uma atividade extremamente complexa. Há que se considerar que tanto a economia brasileira como a economia capixaba já tinham no radar vários desafios a serem enfrentados. Pode-se dizer, então, que a pandemia da Covid-19 não inaugura uma nova crise, mas aprofunda aquela em que essas economias ainda estavam mergulhadas. $\mathrm{O}$ Observatório do Desenvolvimento Capixaba (ODC), que se dedica sistematicamente às possibilidades de desenvolvimento da economia do Espírito Santo, acompanha as medidas econômicas tomadas e os desdobramentos sobre a dinâmica econômica do Estado. Assim, este artigo contextualiza a problemática que já vinha se desenhando mesmo antes da chegada da doença coronavírus e apresenta algumas propostas tanto em nível macro como em nível microeconômico que, no entender dos pesquisadores do ODC, poderão contribuir para enfrentamento dos desafios que se desenham à frente.

Palavras-chave: Pandemia; coronavírus; desenvolvimento econômico; economia capixaba. 


\begin{abstract}
In the face to the serious crisis that has happened around the world, by the pandemic COVID-19, almost all countries have adopted measures to fight the coronavirus basically using strategies of social distancing. These measures directly affect economic activity, mainly on workers' income and employment, led to many governments to adopt measures to mitigate the effects of the paralysis that affect many activities, such as industry, commerce, services and agriculture. However, it is too early to say about the effectiveness of these decisions, because the construction of scenarios regarding the behavior of the economy, even in the short term, has become an extremely complex activity. It must be considered that both the Brazilian economy and the economy of the Espírito Santo state already had several challenges to be faced. It can be said, then, that the COVID-19 pandemic does not inaugurate a new crisis, but deepens the one in which these economies were still immersed. The Observatório do Desenvolvimento Capixaba - ODC, which systematically dedicates itself to the study of the possibilities of developing of the Espírito Santo state, closely monitors all the economic measures taken and their consequences on the economic dynamics of the State. Thus, this article contextualizes the problem that had been developing even before the arrival of the coronavirus and presents some proposals both at the macro level and also at the microeconomic level that, in the opinion of ODC researchers, may contribute to face the challenges that are being drawn forward.
\end{abstract}

Keywords: coronavirus pandemic, economic development, Economy of the Espírito Santo State.

\section{INTRODUÇÃO}

A situação da economia mundial mudou radicalmente nos últimos meses, desde que a epidemia do novo coronavírus, que ficou inicialmente circunscrita à China e a alguns países europeus, alcançou outros países e, saindo do controle de autoridades sanitárias nacionais, transformou-se em uma pandemia, reconhecida pela Organização das Nações Unidas e Organização Mundial da Saúde (ONUOMS), no início de março.

Os impactos econômicos que inicial e supostamente ficariam restritos a poucos países, rapidamente se estenderam para todos os continentes e atingiram severamente tanto os mercados reais quanto os financeiros globais. A economia mundial passou a caminhar rumo a uma grave recessão, com perspectiva de uma forte retração do Produto Interno Bruto (PIB) mundial, queda da renda e aumento do desemprego. É unânime a ideia de que, uma vez que tal problemática $\mathrm{e}$ complexidade são inéditas, mesmo com todas as experiências acumuladas em crises anteriores, fazer projeções macroeconômicas com algum grau de confiança tornou-se uma tarefa extremamente complexa.
Os países, então, passaram a mobilizar um poderoso arsenal de instrumentos econômicos para amortecer os impactos negativos da crise: bancos centrais iniciaram a redução de juros e a maioria dos governos se voltou para uma política econômica expansionista, com aumento do gasto público. O pacote norteamericano de US\$ 2 trilhões que destinou recursos para a saúde, para reposição de renda das famílias e para apoio às empresas, se constituiu como face emblemática da guinada ideológica na condução da política econômica mundial, saindo de um viés liberal, com pouca intervenção do estado, e ganhando traços keynesianos, ações entendidas como necessárias para enfrentar a crise que se desenhou.

No Brasil, vale dizer que a economia já vinha enfrentando uma série de crises e mesmo antes da chegada da Covid-19 já era claro que o país atravessaria momentos difíceis: era a certeza de uma economia combalida por equívocos da política econômica (BARBOSA FILHO, 2017).

Vale citar, por exemplo, dentre as mais recentes, aquela oriunda dos desdobramentos da crise financeira mundial de 2008 a 2010. Esta crise 
resultou duas recessões técnicas, 2015 e 2016, além das que provieram das reformas que foram implementadas a partir de 2016, as quais causaram baixa dinâmica econômica nos anos seguintes.

A sobreposição da crise do coronavírus sobre aquela pré-existente também forçou - embora com grande resistência do próprio governo - uma nova agenda de ações. A política econômica brasileira, a fim de responder aos desafios do aumento do desemprego e à queda abrupta da renda, passou, como em outros países, a prever medidas monetárias e fiscais expansionistas. Do lado monetário, houve redução da taxa de juros e de alíquotas de compulsórios, acompanhadas de medidas para ampliação do crédito. Do lado fiscal, passou-se a mobilizar recursos em um novo orçamento para reduzir o impacto negativo da crise sobre a renda (especialmente dos mais pobres), sobre o emprego e, na medida do possível, sobre a sustentabilidade financeira das empresas, principalmente micro, pequenas e médias.

Realidade semelhante é a que passava a economia capixaba. De acordo com os dados do Instituto Jones dos Santos Neves (IJSN) (2020), em 2019, o PIB capixaba apresentou uma situação de estabilidade sem nenhum avanço em relação a 2018. No acumulado de 2019, embora o comércio varejista ampliado tenha se expandido $5,2 \%$ e os serviços $1,0 \%$, a indústria geral apresentou retração de $-15,7 \%$. Fica claro que a economia capixaba também enfrentaria desafios para dinamizar sua economia em 2020, mesmo sem a crise da pandemia que também se instalou no estado.

O que se pode dizer, entretanto, e com razoável grau de certeza, é que o custo da crise, em termos de PIB e renda do trabalhador, é crescente. Isso significa que, mesmo considerando efetivas as medidas mitigadoras, os riscos de falências de empresas, de aumento do desemprego e até de repercussões em diferentes formas de esgarçamento social, se constituem em cenários que se mostram possíveis diante da gravidade da crise.

Diante desses enormes desafios, o objetivo deste artigo é fazer um rápido diagnóstico da conjuntura econômica brasileira e capixaba e o que razoavelmente pode se esperar para os próximos anos. Também visa apresentar algumas medidas de política econômica e de estratégias empresariais que foram (ou podem ser) tomadas no intuito de mitigar os efeitos da crise que já se instalou no Brasil e no Espírito Santo.

$\mathrm{O}$ artigo está dividido em quatro partes, além desta introdução. A princípio, serão apresentados alguns dados que revelam a situação em que se encontravam a economia brasileira e a capixaba, antes da crise da Covid-19, evidenciando que a situação já era de alerta para essas economias, mesmo antes da chegada da pandemia. Explicita, também, ainda que de modo geral, alguns desdobramentos da atual crise sobre o funcionamento das economias. A segunda parte evidencia algumas medidas estruturais e mais sistêmicas que podem ser tomadas no sentido tanto de enfrentar as consequências econômicas da crise quanto também de lidar, do lado da saúde, com a situação de precariedade da infraestrutura hospitalar no Espírito Santo. A terceira parte expõe os desafios e as principais soluções da gestão pública, tendo-se em vista a necessidade que se tornou premente de fazer a gestão pública via e-government. A quarta parte destaca os impactos e algumas proposições para $o$ enfrentamento da crise, considerando a problemática das cadeias (globais e locais) de suprimento. Seguem, depois, alguns apontamentos, em termos de considerações finais.

\section{O CONTEXTO ECONÔMICO DO BRASIL E DO ESPÍRITO SANTO E OS DESDOBRAMENTOS ECONÔMICOS DO CORONAVÍRUS}

O Brasil, desde o início da década de 1980, vem passando por uma série de crises econômicas e políticas que o 
impediu de superar o processo de semiestagnação que se abateu sobre sua dinâmica econômica. Podem-se enxergar pelo menos três faces desse processo:

(i) os obstáculos aos quais esteve submetida a economia brasileira não têm sido poucos: crise da dívida externa na década de 1980; hiperinflação que se estendeu, em sua fase mais aguda, do início da década de 1980 até a primeira metade da década de 1990; taxas de juros reais elevadas e muito superiores à média internacional; taxas de câmbio reais cíclica e cronicamente apreciadas; descontrole dos gastos públicos e uma maléfica combinação de instrumentos econômicos tanto de contenção da demanda quanto de estrangulamento da produção industrial;

(ii) porquanto, dessa sequência de crises e dificuldades, pode-se dizer que seus desdobramentos impediram o Brasil de manter taxas sustentáveis de crescimento do PIB e continuar o processo de mudanças estruturais necessárias para alcançar a convergência econômica (catching up) compatível com os padrões de renda per capita e de bem-estar dos países avançados. Por essa ótica, pode-se dizer que tem-se caído na "armadilha da renda média" (GALA et al., 2019) ou, também, que o Brasil se tornou um país com o processo de desenvolvimento interrompido e inacabado (FURTADO, 1992); e

(iii) é preciso dizer que os obstáculos que impediram (e continuam impedindo) uma melhor dinâmica brasileira fazem com que o Brasil experimente uma situação de "stop and go", na qual o país experimenta taxas positivas de crescimento por alguns anos, mas que, por não serem sustentáveis, geram recorrentemente ciclos de crise, alternando, então, crescimento e queda como um ciclo infindável.

A atual crise econômica teve início em meados de 2014 e, dentre suas várias consequências, pode-se destacar a forte recessão econômica que levou a um recuo no PIB por dois anos consecutivos (2015 em 3,50\% e 2016 em 3,35\%) (IBGE, 2020). O Gráfico 01 mostra o desempenho do PIB trimestral brasileiro e evidencia o tamanho da crise em que esteve submerso. É possível dizer que a recuperação que se seguiu é tida como fraca e insuficiente para sua dinamização. Ou seja, as taxas de crescimento apresentadas a partir de 2017 apenas caracterizaram o fim da recessão técnica, mas não significaram o fim da crise.

Gráfico 1: PIB trimestral do Brasil - variação em relação ao trimestre anterior

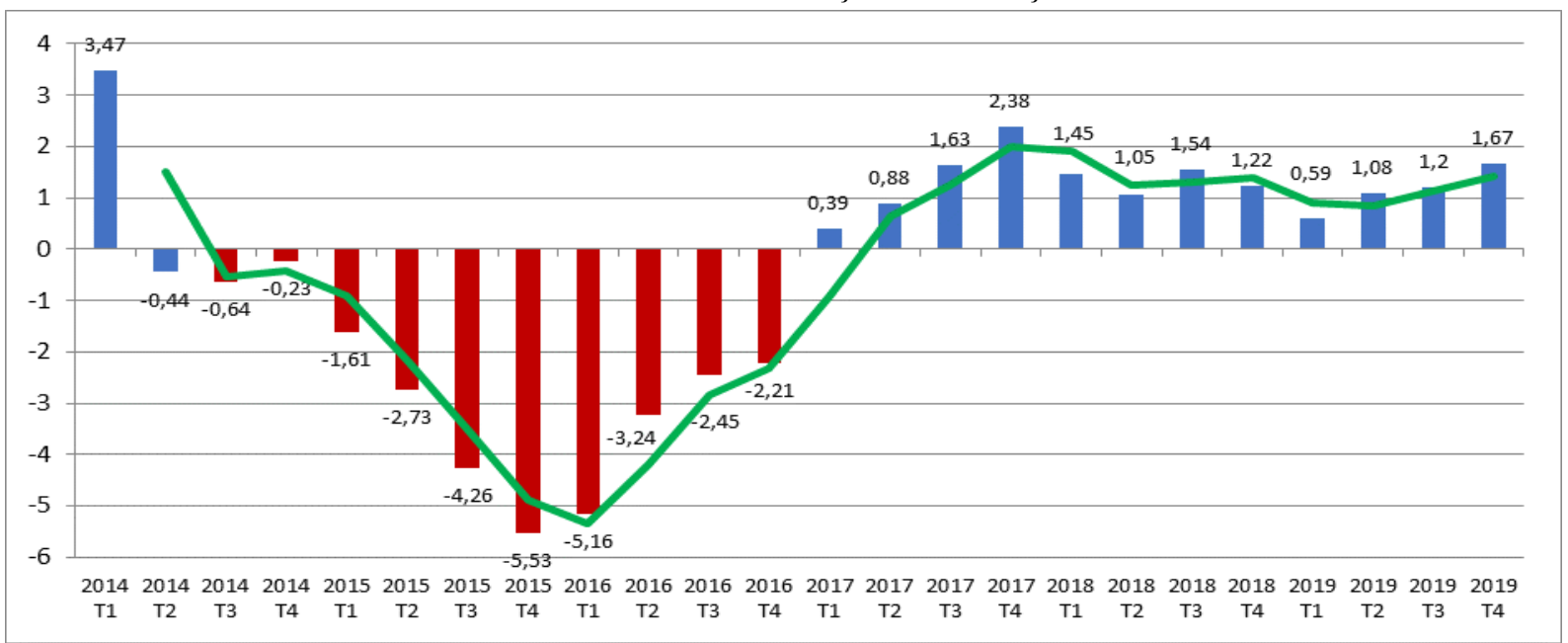

Fonte: elaboração própria a partir dos dados das Contas Nacionais - IBGE (2020)

A crise também gerou desemprego, que chegou a atingir uma taxa de $13,7 \%$ no primeiro trimestre de 2017. Embora as taxas de desemprego tenham arrefecido a 
partir de 2016, conforme Gráfico 2 abaixo, são evidentes os processos de precarização do trabalho, principalmente após as reformas trabalhistas que foram implementadas em 2017.

Gráfico 2: Taxa trimestral de desocupação no Brasil - 2012 a 2019

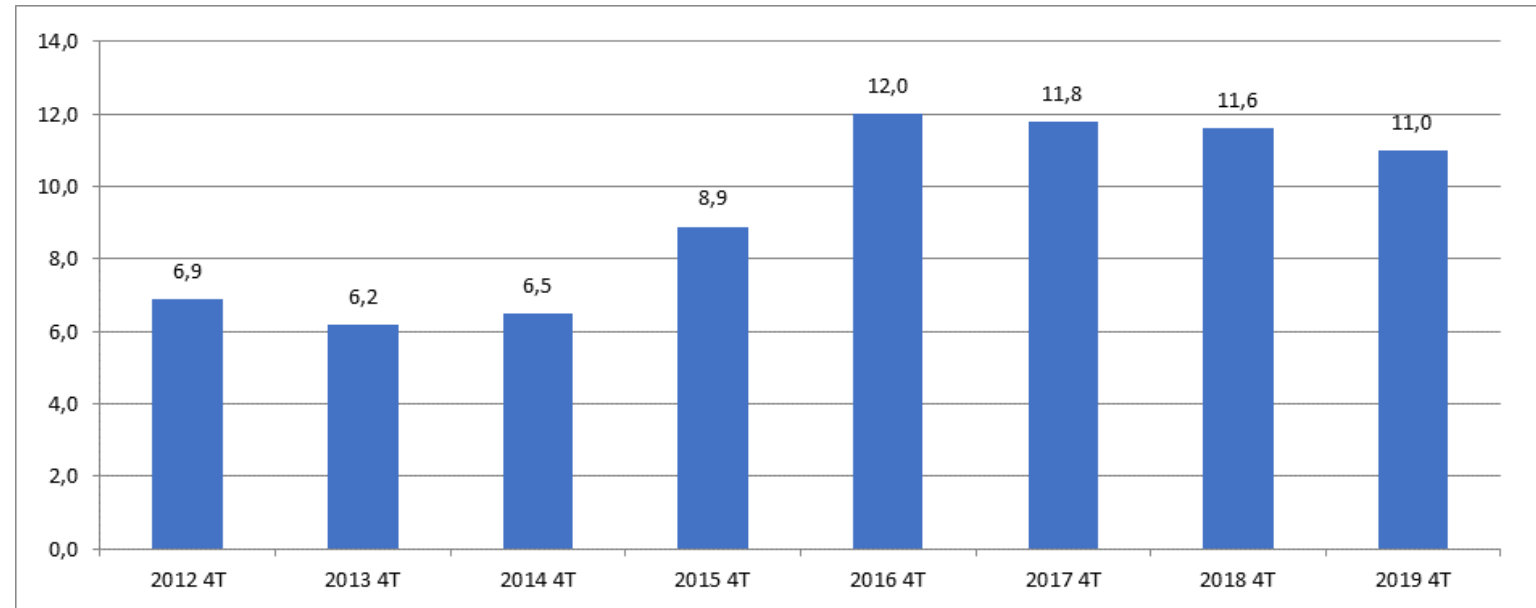

Fonte: elaboração própria a partir dos dados da Pesquisa Nacional por Amostra de Domicílios (Pnad) Contínua - IBGE (2020a).

A concentração de renda dos brasileiros foi outra variável duramente atingida pela crise. $\mathrm{O}$ indicador de desigualdade da renda, medido pela Fundação Getúlio Vargas, por intermédio do Instituto Brasileiro de Economia da (FGV/IBRE), atingiu, em 2019, o maior o patamar da série histórica. $\mathrm{O}$ indicador apresentado no Gráfico 3 é o índice de Gini/Renda. Quanto mais próximo de 1, maior é a desigualdade de renda entre os brasileiros. A pesquisa evidenciou, também, que as pessoas com renda menor são as que mais sofrem os efeitos da crise.

Gráfico 3: Índice de Gini/Renda - desigualdade da renda no Brasil - 2015 a 2019

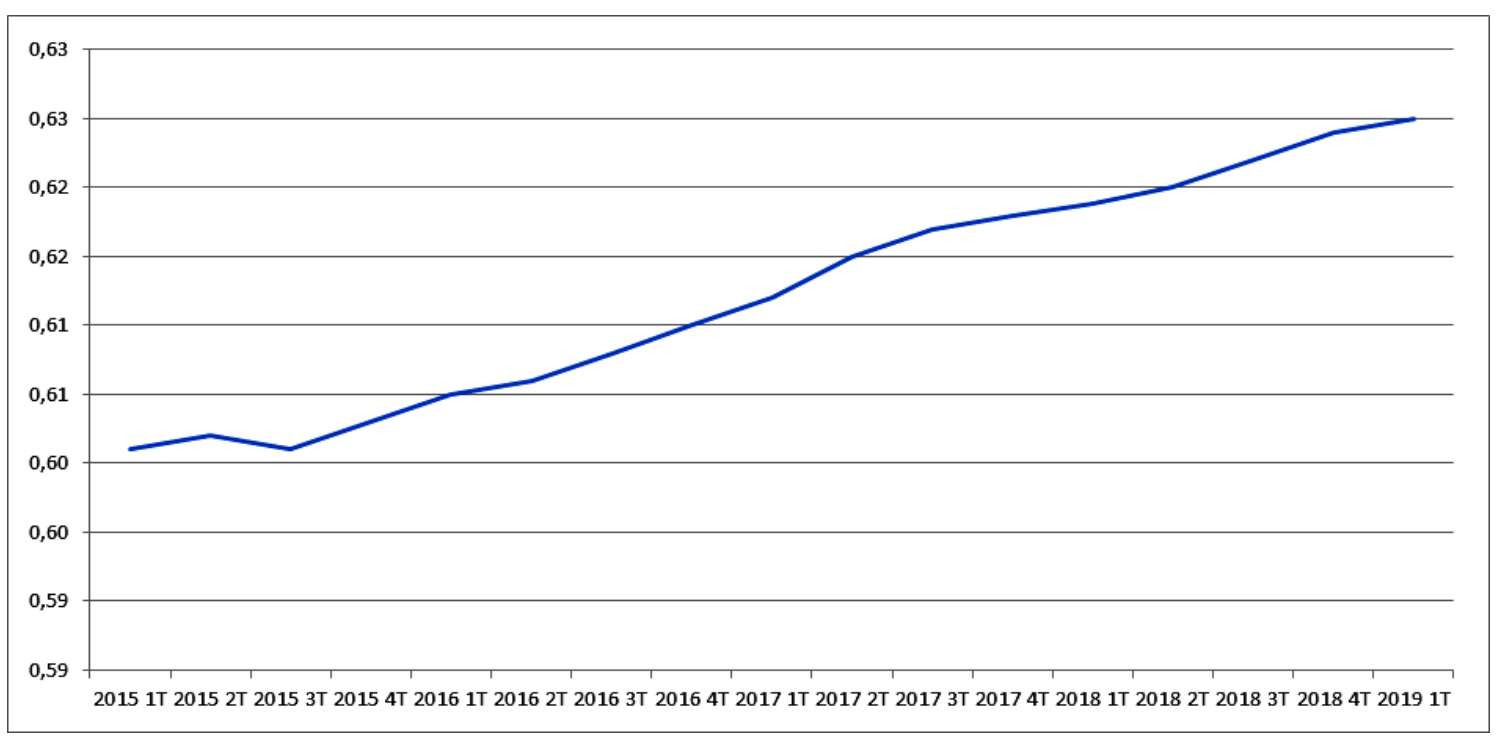

Fonte: FGV/IBRE (2019). 
Essa realidade ao fim de 2019, que já apontava para desafios a serem enfrentados pela economia brasileira, também pode ser aplicada à economia capixaba. De fato, depois que o PIB trimestral capixaba se recuperou de uma crise, com taxas negativas que se estenderam desde o início de 2016 até meados de 2017, os dados para 2019 já apontavam novamente para uma tendência de queda, como apresenta o Gráfico 4.

Gráfico 4: PIB trimestral capixaba - variação \% acumulada em quatro trimestres em relação a igual período anterior - 2016 a 2019

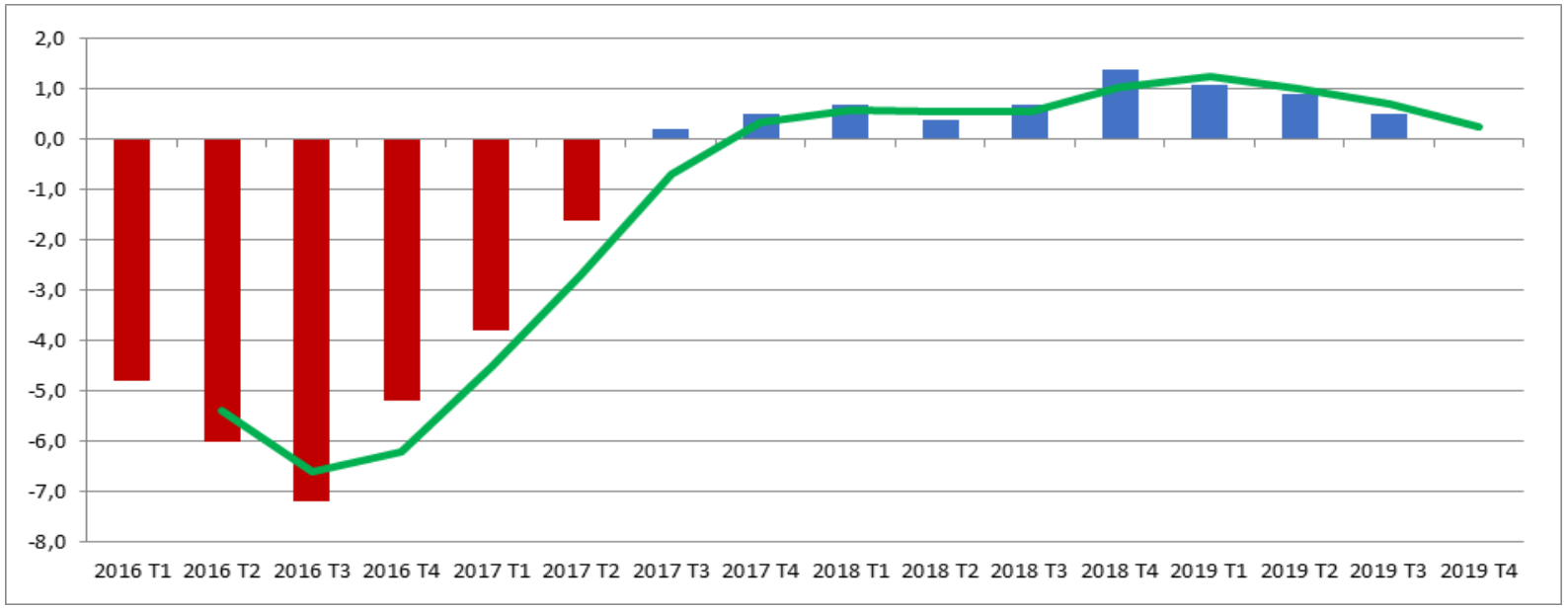

Fonte: IJSN (2020).

A mesma problemática se repete também em relação à taxa de desocupação para o Espírito Santo. O Gráfico 5 deixa claro que, depois de alcançar o patamar de $14,7 \%$ no primeiro trimestre de 2017 , o emprego mostrou uma leve recuperação.
Contudo, também para o Espírito Santo, é possível dizer que a queda na taxa de ocupação veio acompanhada do aumento do emprego informal e de uma precarização do trabalho.

Gráfico 5: Taxa trimestral de desocupação no Espírito Santo - 2012 a 2019

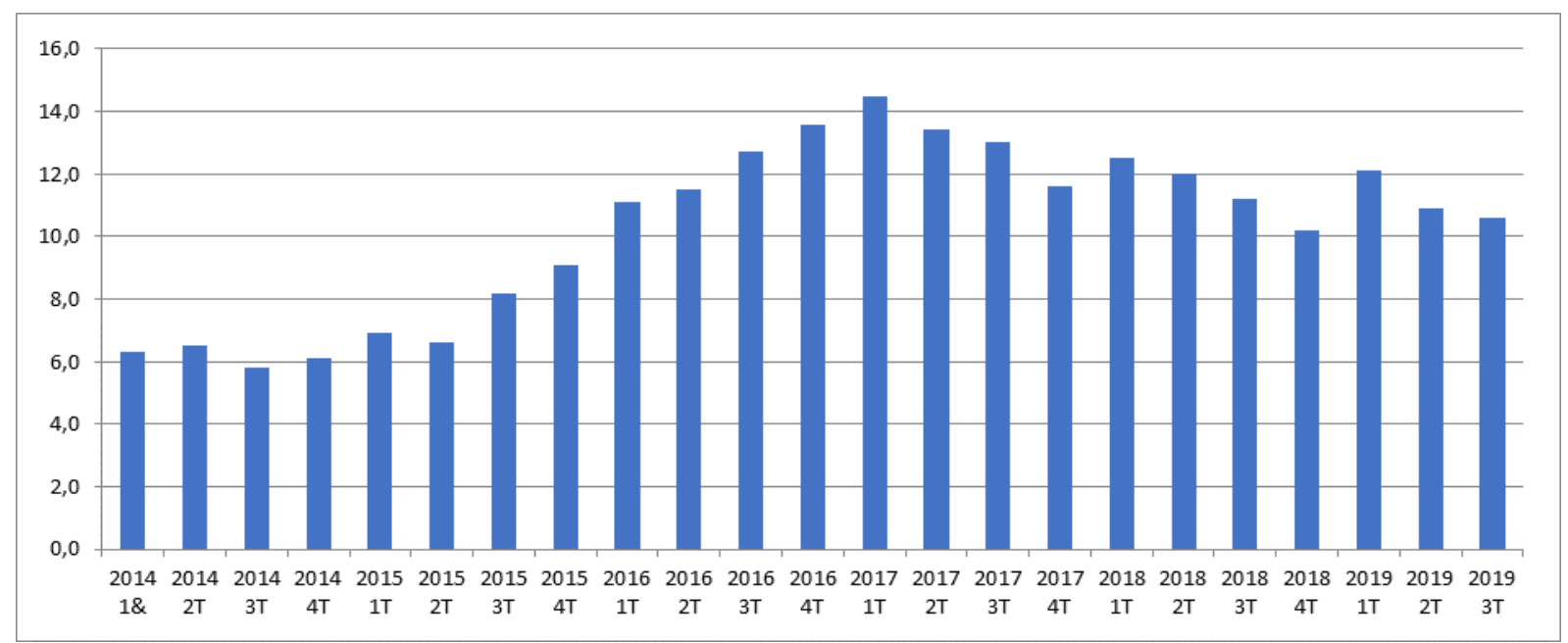

Fonte: Elaboração própria a partir dos dados da Pnad Contínua - IBGE (2020b).

Do exposto acima, fica claro que a chegada do coronavírus não inaugurou uma crise na economia brasileira e nem mesmo na capixaba, mas aprofundou uma situação que já se desenhava complexa e apontava para uma estagnação dessas economias. 


\subsection{A PROBLEMÁTICA ECONÔMICA DA COVID-19}

A pandemia associada ao novo coronavírus (Covid-19) jogou sobre a economia brasileira e a capixaba uma série de incertezas e uma abrupta interrupção das atividades econômicas, o que deve implicar em uma retração superior aos níveis registrados na crise financeira internacional de 2007-2009.

Economicamente, desde que a situação da Covid-19 se agravou, as medidas de isolamento social provocaram um "choque" na economia tanto pelo lado da oferta quanto pelo lado da demanda. Vale dizer que quanto mais a crise se agrava, mais se sente a profundidade desses choques e, por conseguinte, maiores serão as dificuldades que a economia terá que enfrentar em seu processo de recuperação.

Pelo lado da oferta, há impactos derivados da limitação física ao deslocamento de trabalhadores e também da quebra das cadeias de produção, que, em alguns casos, prejudicou a entrega de insumos e matérias primas, ainda que temporariamente.

Pelo lado da demanda, a restrição à mobilidade dos consumidores, o aumento do nível de incerteza e a já constatada queda na renda provocaram uma queda nos níveis de consumo. Além disso, a suspensão das atividades das escolas e das universidades fez cessar uma demanda específica desses setores que envolvem, transporte escolar e outras atividades daí derivadas. Outros segmentos, como turismo e aviação, aparecem como aqueles que sentiram fortemente a retração da demanda por seus produtos e serviços.

Vale dizer que ainda há de se considerar a transmissão do choque econômico internacional que se imporá sobre a economia brasileira e a capixaba. Por um lado, a paralisação industrial em vários países tende a diminuir o fluxo de insumos necessários para a economia interna, ou seja, há, para alguns casos, risco potencial de interrupção em certas cadeias produtivas em que a economia brasileira e a capixaba estão inseridas. Por outro, o arrefecimento da demanda global impactará as exportações capixabas que tinham a China e Estados Unidos como principais demandantes dos produtos exportados pelo Espírito Santo. Essa baixa dinâmica mundial ainda deverá potencializar outro choque negativo de preço das commodities ${ }^{l}$, diminuindo, ainda que em curto prazo, a rentabilidade das exportações.

Assim, em situações em que os choques acontecem tanto pelo lado da oferta quanto pelo da demanda, que é a característica marcante dessa pandemia, as decisões econômicas, sejam de produção ou de investimento, passam a ser eivadas de incertezas. De acordo com os dados levantados pelo FGV/IBRE/ (2020), por exemplo, em comparação a março de 2019, o índice de confiança caiu $37,9 \%$ para os empresários industriais do setor de bens intermediários, $36,2 \%$ no setor de bens duráveis e $52,3 \%$ no setor de bens de consumo.

No sentido de reverter tais situações de incerteza e criar mecanismos mínimos para que a economia continue funcionando, os Estados Unidos, como já foi indicado, anunciaram medidas que representam $6,3 \%$ do PIB. Por sua vez, o Reino Unido e a Espanha apontaram pacotes que constituem, em cada um desses países, algo em torno de $17 \%$ do PIB (FGV, 2020a). No caso brasileiro, entretanto, as medidas divulgadas compõem apenas uma pequena parte do PIB. Há, de forma geral, uma percepção de que as medidas brasileiras ainda são

\footnotetext{
1 Em março de 2020, o preço das commodities agrícolas caiu 5,8\% em relação a janeiro; metais e minerais apresentaram queda de $11,6 \%$ e aquelas ligadas à energia tiveram uma queda de 43,6\%. O índice de todas as commodities do FMI caiu $21,5 \%$. O petróleo apresentou forte queda de US\$ 69/barril em janeiro para US\$ 22,7/barril em abril (IPEA, 2020)
} 
insuficientes para resolver a complexidade da crise que já está instalada.

No Espírito Santo, as medidas anunciadas pelo Governo Estadual ainda não ultrapassaram a ordem de $1 \%$ do $\mathrm{PIB}$ capixaba. Em que pese, entretanto, o fato de o valor prenunciado ser modesto face à crise que assola o estado, a natureza das medidas divulgadas é majoritariamente voltada ao alívio do fluxo de caixa das empresas, não privilegiando o pilar da criação da rede de proteção social.

\section{POLÍTICAS DE ENFRENTAMENTO À COVID-19: A TOMADA DE DECISÕES MACROECONÔMICAS E ESTRUTURAIS}

Em tempos de crise, do ponto de vista econômico, as teorias de cunho keynesiano, que apregoam a necessária intervenção do Estado para a retirada do país de uma crise, são amplamente evocadas, uma vez que há praticamente um consenso sobre a incapacidade dos mercados de lidarem com as crises. Nesse sentido, o Observatório do Desenvolvimento Capixaba (ODC) acompanha atentamente os governos de cada país, estado ou município na apresentação de seus pacotes/planos para o enfrentamento da crise da Covid-19 no mundo.

De acordo com a Fundação Getúlio Vargas (FGV), as políticas voltadas ao enfrentamento dessa crise estão alicerçadas basicamente em 03 pilares:

i) aliviar o fluxo de caixa das empresas;

ii) repor a renda das famílias; e

iii) reforçar a capacidade dos sistemas de saúde.

O ODC, alinhado com essas frentes de ação, aponta para a necessidade de medidas econômicas e de proteção social que terão efeitos positivos se coordenadas e integradas em todas as esferas de governo, o que sistematicamente ainda não aconteceu, gerando uma série de ineficiências operacionais, sobreposição de ações e, sobretudo, desperdícios de recursos públicos. A figura abaixo apresenta a proposição do ODC para uma aproximação e gestão integrada das ações necessárias ao enfrentamento da crise.

Figura 1: Ações integradas e coordenadas para o enfrentamento da crise da Covid-19

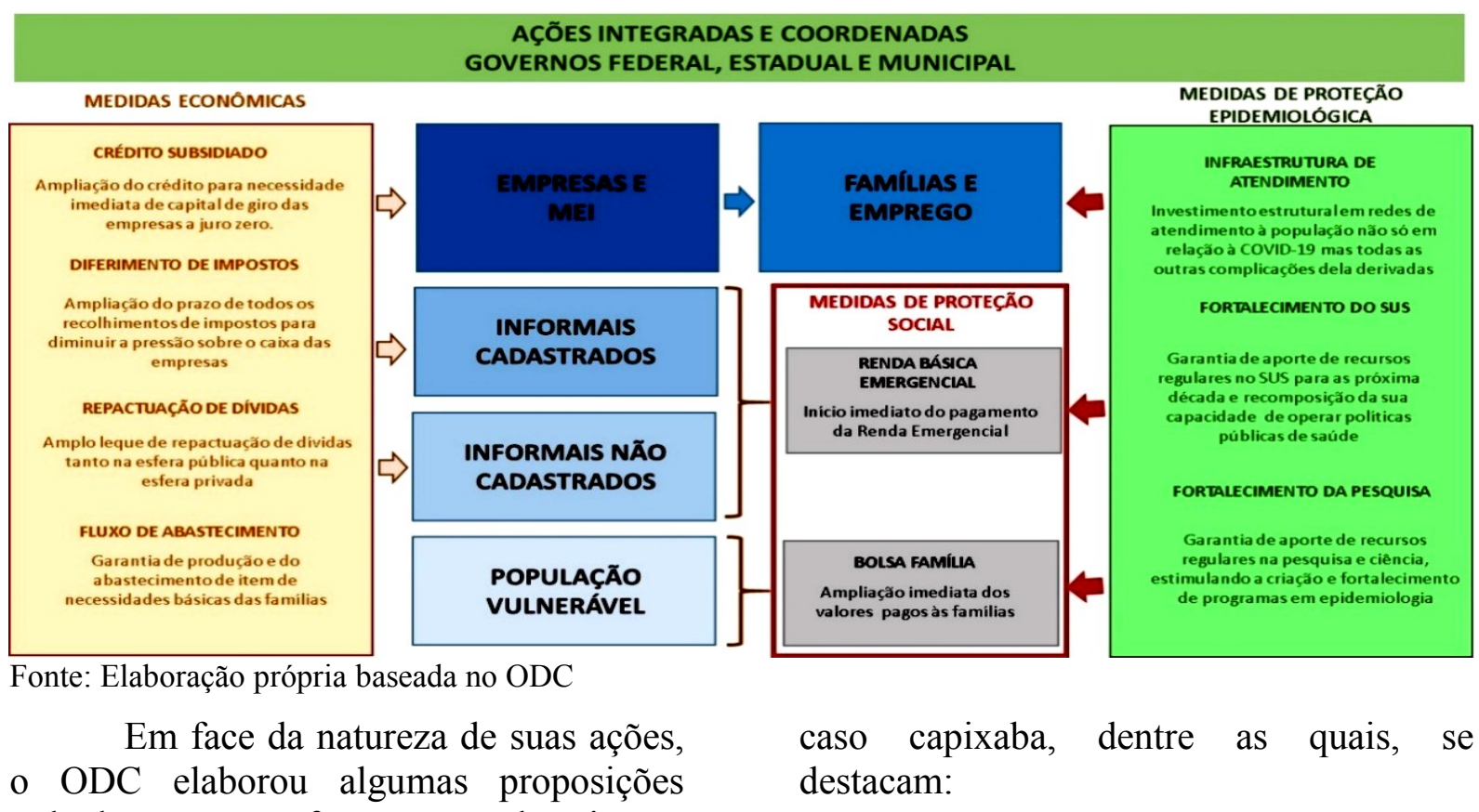
voltadas para o enfrentamento da crise no 


\subsection{CRÉDITO SUBSIDIADO E DIFERIMENTO DE IMPOSTOS}

A crise causada pela pandemia da Covid-19 se sobrepôs às modestas taxas de crescimento da economia que já vinham sendo observadas no Brasil e no Espírito Santo. Ao mesmo tempo em que as medidas para reduzir a disseminação da doença tornaram-se mais restritivas e os impactos mais severos, ampliou-se o debate sobre as medidas que poderiam ser adotadas. Como não deveria deixar de ser, o mercado de crédito logo foi apontado como instrumento essencial de estímulo à economia por razão simples: a maior disponibilidade de crédito permite a expansão da demanda efetiva e, com isso, garante o crescimento da renda e do emprego.

Apesar da clara relação entre crédito e crescimento, o padrão de funcionamento do mercado de crédito, durante as crises econômicas anteriores, deixou algumas lições importantes que precisam ser consideradas. Nos momentos de crise, a ausência de referências para a formação de expectativas quanto ao futuro induz as instituições bancárias a exercerem sua preferência pela liquidez, ou seja, os bancos se tornam mais cautelosos e limitam a concessão de crédito.

A pergunta então é: diante da deterioração do estado de confiança na economia, o que pode ser feito? A resposta tem sido a utilização vigorosa dos instrumentos de política monetária para prover liquidez (redução da taxa de juros básica, redução do compulsório etc.). E essa tem sido a linha de atuação do governo brasileiro: houve redução da taxa de juros para $3,75 \%$ a.a. e redução da alíquota de depósitos compulsórios para 17\%. Essas medidas representam uma liberação de liquidez de R \$ 1,2 trilhão.

Para que essa liberação de liquidez seja efetiva para ampliar os níveis de crédito, é consenso o papel exercido pelos bancos públicos e de desenvolvimento ao atuarem de forma compensatória em relação ao restante do sistema financeiro privado. Além disso, a política monetária isolada, na ausência de um esforço físcal de ampliação de gastos, não é suficiente para sustentar o emprego e a renda na economia. No Espírito Santo, várias medidas já foram adotadas pelo governo do estado para amenizar os impactos econômicos da crise (Quadro 1).

Quadro 1: Medidas anunciadas pelo Governo do Estado

\begin{tabular}{|c|c|}
\hline Programa & Objetivo \\
\hline Linha do Emprego & $\begin{array}{l}\text { Microempresas que faturam até } \mathrm{R} \$ 360 \text { mil por ano poderão pegar crédito, com o } \\
\text { Banestes ou o Bandes, no valor de } \mathrm{R} \$ 31,5 \text { mil. O objetivo é pagar o salário dos } \\
\text { empregados. No período do financiamento não poderá haver demissões. O prazo de } \\
48 \text { meses e correção pela taxa Selic: } 3,75 \% \text { ao ano. }\end{array}$ \\
\hline $\begin{array}{l}\text { Empréstimos para } \\
\text { MEIs }\end{array}$ & $\begin{array}{l}\text { Liberação de R\$ } 5 \text { mil, sem juros, via Banestes, para Microempreendedor Individual } \\
\text { (MEI), artesãos, representantes da economia solidária e trabalhadores autônomos. } \\
\text { Carência de seis meses e prazo de quitação de } 24 \text { meses. O empréstimo poderá ser } \\
\text { feito para qualquer finalidade. }\end{array}$ \\
\hline $\begin{array}{l}\text { Financiamento } \\
\text { para Pequenas e } \\
\text { Médias Empresas } \\
\end{array}$ & $\begin{array}{l}\text { As empresas com faturamento entre } \mathrm{R} \$ 360 \text { mil e } \mathrm{R} \$ 10 \text { milhões por ano também } \\
\text { contarão com uma linha de crédito do Banestes. O financiamento terá que ser pago } \\
\text { em até } 36 \text { meses e a taxa de juros é de } 3,75 \% \text { ao ano. }\end{array}$ \\
\hline $\begin{array}{l}\text { Demais } \\
\text { Financiamentos }\end{array}$ & $\begin{array}{l}\text { Aos demais empresários está disponível o valor total de R\$ } 300 \text { milhões, operados } \\
\text { pelo Banco de Desenvolvimento do Espírito Santo (Bandes) e pelo Banestes. A } \\
\text { correção é de } 7,25 \% \text { ao ano. }\end{array}$ \\
\hline $\begin{array}{l}\text { Adiamento do } \\
\text { Simples }\end{array}$ & $\begin{array}{l}\text { O pagamento do Imposto sobre Circulação de Mercadorias e Serviços (ICMS) do } \\
\text { Simples Nacional, que cabe ao Estado, será prorrogado por } 90 \text { dias, sem a adição de } \\
\text { juros. Isso representa R\$ } 100 \text { milhões na postergação do recebimento de impostos. }\end{array}$ \\
\hline
\end{tabular}

Fonte: SEDES 
A relevância e o alcance das medidas residem principalmente no público diretamente afetado: os pequenos negócios, que sofrem o impacto imediato da redução da circulação pública, e os trabalhadores de renda mais baixa, que em condições normais já possuem pouco acesso à rede de proteção social e que são

Figura 2: Operações de crédito

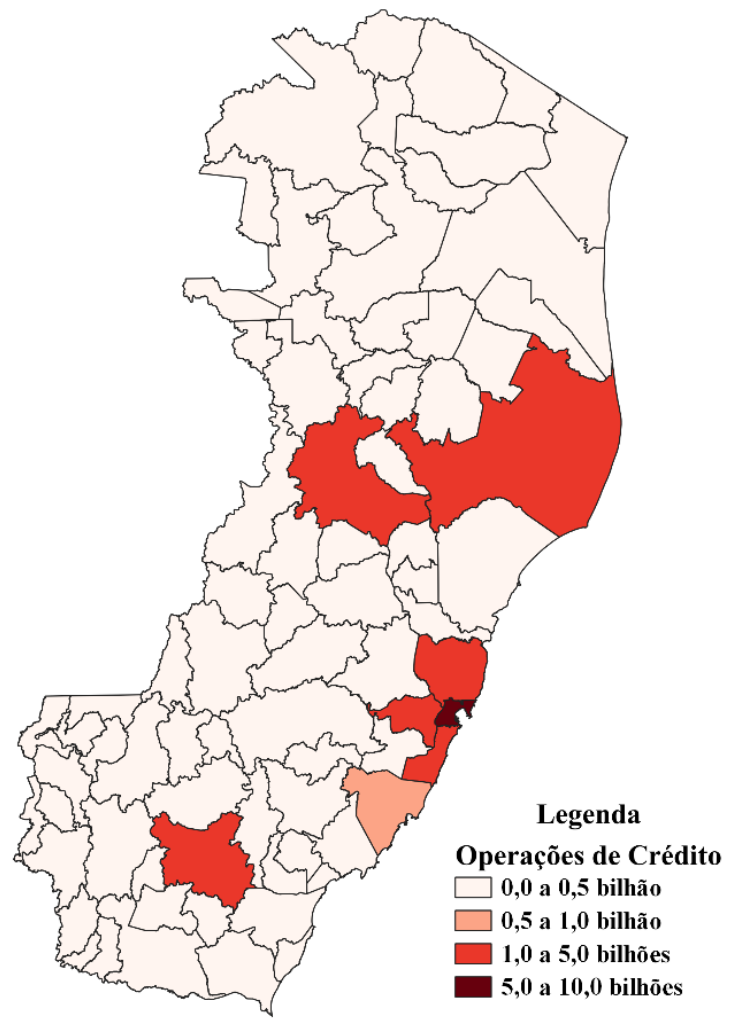

Fonte: Banco Central e IJSN. Elaboração própria.

$\mathrm{Na}$ Figura 2 é indicada a distribuição do volume das operações de crédito (pessoa física e jurídica) nos municípios do Espírito Santo. Em razão da histórica concentração da renda e da população, as operações de crédito seguem a mesma tendência. Os oito municípios que sobressaem no mapa concentram mais de $70 \%$ do total do crédito no estado.

Na Figura 3 é apresentada a relação entre o volume de crédito e o PIB dos municípios, que tem sido utilizado como um importante indicador das condições e da profundidade do mercado de crédito bancário nas regiões. Em 72 dos 78 mais vulneráveis às oscilações dos preços de bens e serviços essenciais.

Porém, um aspecto muitas vezes negligenciado nas discussões sobre o papel do crédito na economia é sua distribuição heterogênea no território e como isso pode reforçar as disparidades regionais.

Figura 3: Crédito/PIB

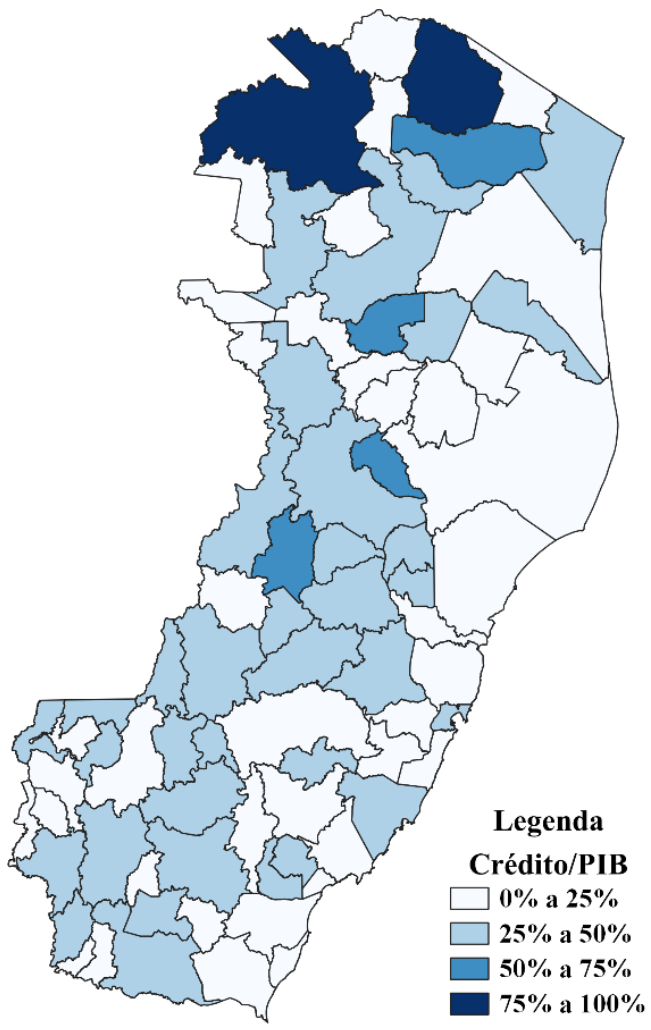

Fonte: Banco Central e IJSN. Elaboração própria.

municípios capixabas, o mercado de crédito é inferior a $50 \%$ do PIB, patamar ainda considerado insuficiente. Entretanto, cabe observar que todos os municípios do Espírito Santo contam com, pelo menos, uma agência bancária.

$\mathrm{O}$ aspecto regional ganha relevância no debate porque, em momentos de instabilidade, são os municípios mais periféricos, caracterizados por maior preferência pela liquidez, que apresentam maior restrição financeira em razão dos vazamentos de recursos em direção aos municípios centrais (efeito substituição), atraídos pelas economias de escala, 
aglomeração, localização e urbanização. Assim, a ampliação da capacidade produtiva nos municípios periféricos fica limitada basicamente ao autofinanciamento das empresas. Além disso, o menor volume de recursos públicos afeta proporcionalmente mais os municípios com maiores parcelas da população, dependentes dos serviços públicos básicos.

Por fim, cabe observar o papel do crédito não somente na ampliação do consumo e da renda no curto prazo, mas também em relação à recuperação em longo prazo das regiões. Nesse caso, os investimentos em infraestrutura (energia elétrica, logística e saneamento) são importantes para gerar estímulos complementares aos investimentos privados nos demais setores da economia (efeitos multiplicadores) e para aumentar a competitividade regional.

\subsection{RENDA MÍNIMA PARA FAMÍLIAS EM SITUAÇÃO DE VULNERABILIDADE}

De acordo com o IJSN (2019a), o estado possui cerca de 919 mil pessoas que vivem com menos de $\mathrm{R} \$ 425,22$ por mês e cerca de 575 mil pessoas vivendo com menos de R\$ 146,90 mensais. Esses valores representam a linha de corte que define a pobreza e a extrema pobreza, de acordo com o Banco Mundial. Assim, o estado possui o equivalente a quase $23 \%$ da população vivendo em condição de pobreza e $14,3 \%$ em condição de extrema pobreza. Ressalta-se que a base de dados utilizada foi o Cadastro Único (CADÚNICO), que incorpora dados de famílias que tenham renda familiar per capita de até meio salário mínimo ou renda familiar de até três salários mínimos. Trata-se de uma fonte relevante para análise da pobreza, uma vez que permite o acesso das famílias aos programas sociais, dada sua abrangência quase censitária.

Ademais, o estudo mostra que a maior concentração da pobreza no estado está localizada na Região Metropolitana da Grande Vitória (RMGV) e em regiões do interior como Caparaó, Noroeste e Nordeste.

$\mathrm{Na}$ ausência da crise do coronavírus, o volume de recursos anual necessário para retirar a população capixaba da linha da extrema pobreza, isto é, possibilitar que cada cidadão capixaba tenha renda mensal acima de R\$146,90, é de R\$ 633 milhões. Para eliminar a pobreza, o volume de recursos anual necessário é da ordem de R \$ 3,2 bilhões. Tal situação é profundamente agravada hoje já que essas famílias veem ainda mais reduzidas $\mathrm{s}$ suas chances de provisão de recursos até mesmo para alimentação. Nesse sentido, o ODC propõe uma articulação dos governos em todos os níveis para que seja garantida renda necessária para a sobrevivência dessas pessoas.

\subsection{RENDA MÍNIMA PARA TRABALHADORES INFORMAIS}

Para os trabalhadores informais, que inclui os artesãos, os inseridos na economia solidária, motoristas de aplicativos, taxistas, entre outros, a proposta do governo estadual é a liberação de um empréstimo de $\mathrm{R} \$ 5.000,00$ com carência de 06 meses e parcelamento em 24 meses. Para essa parcela da população, a proposta básica do ODC é, em primeiro lugar, garantia de uma renda mínima emergencial e, apenas de forma complementar, uma política facultativa de empréstimo.

Soma-se a isso o fato de que em tempos de incerteza sobre o curso da economia, as pessoas elegíveis para a linha de crédito proposta poderão ficar receosas em assumir o risco de recorrer a este empréstimo. Pode acontecer, também, de assumirem a dívida e ficarem, no futuro, inadimplentes, agravando ainda mais suas condições de vulnerabilidade. 
Nesse cenário, não é possível contar apenas com a execução de programa voltado para garantir a renda imediata da população capixaba exclusivamente alicerçado sob empréstimos como proposto pelo governo estadual. Espera-se a implementação de um robusto programa de transferência de renda imediata para a população capixaba, garantindo condições dignas de sobrevivência durante o pico da crise do Coronavírus no estado, assim como o bem-estar da sociedade na fase de retomada do crescimento econômico.

\subsection{INFRAESTRUTURA SOCIAL DE SAÚDE E INVESTIMENTOS PARA A RETOMADA DO \\ DESENVOLVIMENTO ECONÔMICO}

Em todo o mundo, um dos pilares da política de enfrentamento da Covid-19 é o investimento prioritário em infraestrutura social para a saúde e investimentos em obras diversas de infraestrutura, que além de serem fundamentais para $o$ desenvolvimento econômico e social, são fontes de geração de empregos.

No Espírito Santo, há inúmeras oportunidades de investimentos em infraestrutura que precisam ser lideradas pelo governo do estado. No início do mês do abril de 2020, o ODC, em uma de suas notas sobre a Covid-19, mostrou a necessidade de repensar as ações para que o desenvolvimento alcance, de forma mais igualitária, todas as microrregiões do Espírito Santo. Isso porque, historicamente, a economia capixaba se desenvolveu, depois da sua grande crise dos anos 1960, adotando um modelo de desenvolvimento concentrador na Região Metropolitana. A tabela abaixo mostra algumas evidências dessa necessidade.

Tabela 1 - Evidências das necessidades em infraestrutura social no Espírito Santo

\begin{tabular}{|c|c|c|c|}
\hline & $\begin{array}{c}\text { SANEAMENTO } \\
\text { BÁSICO }\end{array}$ & SAÚDE & HABITAÇÃO \\
\hline Microrregião & $\begin{array}{l}\text { \% das famílias que jogam } \\
\text { esgoto a céu aberto, usam } \\
\text { fossas ou não têm } \\
\text { tratamento de esgoto (1) }\end{array}$ & $\begin{array}{c}\text { Relação de habitantes } \\
\text { por leito de internação } \\
\text { (2) }\end{array}$ & $\begin{array}{c}\% \text { das habitações com } \\
\text { carência de serviços de } \\
\text { infraestrutura (3) }\end{array}$ \\
\hline Nordeste & $44 \%$ & 601,10 & $28,4 \%$ \\
\hline Noroeste & $57 \%$ & 799,30 & $23,0 \%$ \\
\hline Centro Oeste & $48 \%$ & 409,46 & $11,4 \%$ \\
\hline Rio Doce & $35 \%$ & 761,20 & $18,6 \%$ \\
\hline Central Serrana & $75 \%$ & 414,33 & $30,1 \%$ \\
\hline Sudoeste Serrana & $66 \%$ & 466,04 & $26,9 \%$ \\
\hline Metropolitana & $35 \%$ & 516,86 & $14,5 \%$ \\
\hline Litoral Sul & $59 \%$ & 262,72 & $36,5 \%$ \\
\hline Central Sul & $43 \%$ & 450,73 & $11,8 \%$ \\
\hline Caparaó & $40 \%$ & 507,41 & $21,3 \%$ \\
\hline
\end{tabular}

FONTE: Elaboração própria - (1) DIAS (2018); (2) DataSus (2020); (3) Sedurb (2014)

Os dados apresentados são claros. Em relação ao saneamento básico, existem evidências empíricas de que a falta do tratamento de esgoto provoca perdas nas condições de saúde, faltas no trabalho e queda no rendimento escolar das crianças (DIAS, 2018). As ações poderiam ser voltadas a criar as condições para que os municípios executem os seus respectivos Planos Municipais de Saneamento Básico 
que já definem projetos e ações necessárias.

Por outro lado, a infraestrutura de saúde, pressionada por uma crise no modelo que estamos presenciando, é outro vetor de desenvolvimento e bem-estar da população. É extremamente preocupante que em algumas regiões há apenas 1 leito de internação para mais de 700 habitantes, o equivalente a 1,4 leitos de internação para cada grupo de 1.000 habitantes. De acordo com o DataSus (2020), dos 78 municípios capixabas, $24(30 \%)$ não possuem sequer um leito de internação. A construção de infraestrutura social com base na saúde poderá desenvolver vários elos de diversas cadeias produtivas do Espírito Santo.

A Secretaria de Estado da Saúde (Sesa, 2019) possui uma carteira de projetos integrantes de um conjunto de políticas de inovação em saúde, denominado por aquela Secretaria de "iNova Saúde", a serem executados até o ano de 2022. De acordo com Sesa (2019), fazem parte do "iNova Saúde" propostas para ampliar e adequar a infraestrutura física e tecnológica dos hospitais, reorientar o modelo da atenção e de vigilância em saúde, modernizar e qualificar a resolutividade clínica e a gestão dos serviços, incorporar e desenvolver novas tecnologias e práticas de formação profissional, de inovação de ambientes produtivos em saúde e pesquisa aplicada ao SUS.

A carteira de projetos da Sesa está organizada de acordo com os seguintes eixos:

\section{a) Ampliação e adequação da infraestrutura física e tecnológica}

Ampliação do Hospital e Maternidade de São Mateus: 33 novos leitos obstétricos e neonatais. Construção e funcionamento dos blocos 4 e 5 do Hospital Estadual de Urgência e Emergência (HEUE): 43 leitos de UTI e Pronto Socorro e 132 vagas de estacionamento.

Construção e funcionamento do Hospital Geral de Cariacica: 400 novos leitos.
Ampliação, reforma e funcionamento do Hospital Estadual de Atenção Clínica: 90 leitos.

Construção e funcionamento do Hospital Estadual Roberto Arnizaut Silvares: 340 leitos.

Outras iniciativas de qualificação e modernização: Hospital Dr. Jayme dos Santos Neves, Unidade Integrada Jerônimo Monteiro, Hospital Dório Silva, Hospital Infantil Nossa Senhora da Glória, Hospital Maternidade Silvio Avidos, Hospital Geral de Linhares.

Os investimentos descritos acima são fundamentais para expandir a oferta de leitos no estado. Segundo dados do DataSus (2020), o Espírito Santo possui 7.929 leitos de internação, sendo quase 48\% desses leitos instalados na RMGV. A construção do Hospital Geral de Cariacica é fundamental, considerando que esta cidade possui população estimada de cerca de 387 mil habitantes, segundo Instituto Jones dos Santos Neves (2019), e apenas 333 leitos de internação (DataSus, 2020), além de ser limítrofe da cidade de Viana, que não possui nenhum leito de internação. No norte do estado, Colatina e Linhares, que são cidades-polo, contam, juntas, com apenas 741 leitos de internação.

\section{b) Reorientação do modelo da atenção e de vigilância em saúde}

Expansão da cobertura do serviço de Atendimento Móvel de Urgência (Samu 192) para 87\% da população capixaba.

Implantação do Programa Melhor em Casa por meio da habilitação de 30 Equipes Multiprofissionais em Atenção Domiciliar.

A expansão da cobertura do Samu tem como objetivo melhorar a qualidade do atendimento ao paciente no menor tempo possível e o Programa Melhor em Casa visa reduzir a demanda por atendimento hospitalar, o período de permanência dos usuários internados $\mathrm{e}$ humanizar a atenção à saúde. São programas fundamentais para a melhoria do bem-estar da população capixaba.

c) Modernização e qualificação da resolutividade clínica e a gestão dos serviços

Implantação do modelo de logística integrada 


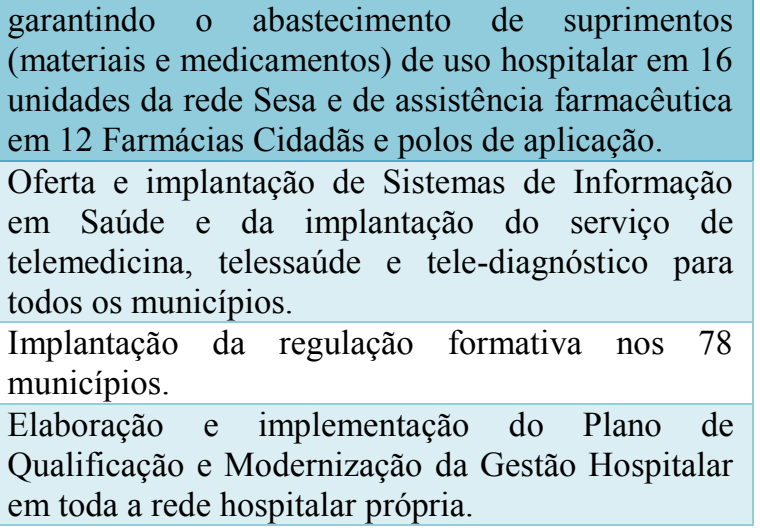

A implantação do modelo de logística integrada para o abastecimento de suprimentos é fundamental para agilizar, inovar e qualificar $\mathrm{o}$ atendimento aos usuários do SUS. O projeto visa prover acesso ágil e adequado à atenção ambulatorial especializada, por meio de processos de regulação assistencial e de ampliação da oferta de serviços, reduzindo o tempo de espera e qualificando o atendimento ao usuário.

Estender a cobertura do serviço de Telessaúde e Tele-diagnóstico para todos os 78 municípios capixabas é outro programa indispensável neste contexto. $\mathrm{O}$ objetivo do programa é tornar a atenção primária à saúde mais resolutiva. No Espírito Santo é executado pelo Instituto Federal do Espírito Santo (Ifes) pela Universidade Federal do Espírito Santo (Ufes) em parceria com a Sesa. O Telessaúde possui duas frentes: i) proporcionar aos profissionais da atenção primária uma segunda opinião (médica, de enfermagem e de nutrição) sobre determinadas situações; ii) teleducação, que permite a realização de cursos e palestras via internet.

O programa Telessaúde é financiado pelo Ministério da Saúde (MS), no entanto, inicialmente, obteve apoio financeiro da Fundação de Amparo à Pesquisa do Espírito Santo (Fapes). Até 2019, o MS financiou regularmente o programa, mas em 2020 o Convênio não foi renovado, inviabilizando a realização de inúmeros projetos que compõem o Telessaúde no Espírito Santo. Assim, neste contexto é fundamental que o Governo do Estado do Espírito Santo, por meio da Fapes, que possui expertise na elaboração de convênios para a execução de projetos como Telessaúde, reúna esforços para a manutenção e expansão do programa.

\section{d) Incorporação e desenvolvimento de novas tecnologias e práticas de formação profissional}

Criação do Instituto Capixaba de Ensino, Pesquisa e Inovação em Saúde (ICEPi)

Um dos projetos estratégicos do iNova Saúde é a criação do ICEPi. Segundo a Sesa (2019), o programa visa desenvolver projetos e atividades voltadas para formação e desenvolvimento de profissionais para o SUS, além de desenvolver e difundir tecnologia, pesquisa científica e inovação tecnológica, realizar o planejamento e desenvolvimento institucional abrangendo as áreas de ensino, pesquisa, extensão e inovação em saúde.

De acordo com Sesa (2019), serão ofertadas, em breve, 44 novas vagas de residência em saúde (especialidades variadas), sendo que a proposta do ICEPi é abrir 1.444 vagas até o final de 2022 .

\subsection{OUTRAS AÇÕES DE PESQUISA EM SAÚDE E OBRAS DE INFRAESTRUTURA}

Além das ações previstas no Planejamento Estratégico do Governo do Estado do Espírito Santo (2019-2022), o estado também precisa liderar um amplo programa de desenvolvimento de produtos e processos para a saúde. O Ifes e a Ufes já estão demonstrando para a sociedade sua capacidade de desenvolver, em seus laboratórios de pesquisas, e em parceria com empresas, uma série de soluções para a saúde.

Naquelas instituições são desenvolvidos equipamentos de proteção individual (EPIs), máscaras de proteção, 
manutenção de equipamentos e de mobiliário para os hospitais, entre outros produtos. Uma das formas de execução deste programa pode ser advinda de um consórcio de empresas. Pode-se propor a criação de uma Sociedade de Propósito Específica (SPE) para resolver estes gargalos com o Estado, garantindo as operações. Ademais, é necessário ainda o apoio à formação de spin-offs tanto nas universidades quanto nas empresas.

O Estado precisa também potencializar a capacidade da Fapes de coordenar a execução técnica e financeira de projetos de pesquisas em diversas áreas, prioritariamente neste momento para a área da saúde. Essa ação já foi sinalizada com o lançamento do Edital específico para apoiar projetos voltados para as soluções para a crise da Covid-19.

No entanto, os projetos devem estar articulados e o apoio da Fundação deve ser perene. A Fapes deve operar não apenas com recursos do Governo do Estado, mas usar toda a sua expertise na captação de recursos para trabalhar em rede com instituições públicas federais e com o setor privado. A Fapes executa com instituições de todo o Brasil o Programa de Pesquisas para o SUS (PPSUS), apoia pesquisas em diversos editais e já apoiou o Programa de Telessaúde no estado.

No que se refere especificamente ao PPSUS, há uma fragilidade na execução do programa no estado relacionada à ausência de articulação para captar as reais demandas do SUS no Espírito Santo. O recurso não pode se limitar a um pequeno grupo de pesquisadores quase que exclusivamente na área de conhecimento da saúde. O estado precisa contar com pesquisas de alto nível na área de gestão da saúde, o que envolve o fortalecimento de grupos de pesquisas nas áreas de ciências sociais aplicadas, ciências humanas, entre outras. Os recursos do PPSUS podem ser utilizados nessas áreas. A crise do coronavírus também expôs a ausência de grupos de pesquisas estruturados nessa temática.

Além da infraestrutura de saúde, o Espírito Santo tem oportunidades de investir em uma série de outras obras de infraestrutura que atualmente se encontra paralisada. Com base no banco de dados do GeoObras, sistema de acompanhamento de obras e serviços de engenharia do Tribunal de Contas do Estado do Espírito Santo (TCE-ES), o estado possui 263 obras paralisadas que somam R\$ 1 bilhão, conforme mostrou ES BRASIL (2020).

O TCE-ES concluiu que entre as principais razões para a paralisação estão razões técnicas, erros de projeto e abandono pela empresa - apenas $6 \%$ das causas estão relacionadas com atuação de Tribunais de Contas, Ministério Público e Judiciário. É necessário empreender esforços junto aos entes federativos responsáveis por essas obras para que elas sejam retomadas.

É imprescindível destacar aqui que desde a crise de 2015 até 2017, os gastos de investimentos do estado capixaba não chegaram a R\$ 1 bilhão por ano. Em 2016, no auge da crise, o Governo do Estado do Espírito Santo executou apenas R\$ 562 milhões em investimentos, como mostrou o Boletim de Economia Capixaba produzido pelo Instituto de Desenvolvimento Educacional e Industrial do Espírito Santo (IDEIES,2020), com base nos dados do Portal da Transparência. $\mathrm{O}$ baixo investimento do governo teve impactos negativos na qualidade dos serviços púbicos, como destacado pelo referido Boletim.

Em que pese o fato de que em crise, as receitas dos governos sejam fortemente afetadas, cumpre ressaltar que o estado capixaba possui excelentes condições de realizar, caso necessário, empréstimos para a execução de obras de infraestrutura em uma posição confortável junto aos credores. Desde 2012, é avaliado com conceito A pelo Tesouro Nacional e a gestão pública estadual possui forte 
reputação por ser vista como comprometida com a responsabilidade fiscal. É preciso que o bom conceito junto aos credores seja convertido em ganhos reais para a sociedade capixaba.

Soma-se a isso a possibilidade do estado realizar obras financiadas por recursos de advindos de compensação ambiental. Nos anos recentes, foram realizados investimentos privados no estado capixaba que resultaram em projetos de compensação ambiental que precisam ter avaliados os estágios de andamento desses projetos. Ademais, o estado sofreu os impactos dos desastres ambientais de Mariana e Brumadinho, necessitando ser empreendidos esforços junto aos grupos privados responsáveis para a execução de projetos que permitam a recuperação, ainda que parcial, dos danos causados em solo capixaba.

A execução perene de obras de infraestrutura é fundamental para a geração de empregos, para potencializar outras cadeias produtivas e para promover o bemestar da sociedade.

\section{POLÍTICAS DE ENFRENTAMENTO À COVID-19: REFLEXÕES E SUGESTÕES À GESTÃ̃ PÚBLICA NOS CENÁRIOS PANDÊMICO E PÓS-PANDÊMICO}

As consequências da pandemia causada pelo novo coronavírus se apresentam como o maior desafio da gestão pública dos últimos 100 anos. Não restam dúvidas de que a política de isolamento social foi necessária para buscar o achatamento da curva de contágio do novo coronavírus e dar maior tempo aos sistemas de saúde para se organizarem.

No Brasil, inclusive no estado do Espírito Santo, o isolamento social esteve abaixo da recomendação da Organização Mundial de Saúde (OMS), de 70\% (MIOTTO E PAIXÃO, 2020). Na prática, os governos estaduais tiveram que assumir a liderança das políticas de isolamento social visto que o Governo Federal se tornou fonte de problemas diversos de coordenação de esforços federativos.

Os serviços essenciais também foram afetados pela descoordenação federativa que prejudicou os esforços e planos de combate. A crise revelou os desentendimentos federativos sobre a interpretação das formas de enfrentamento do vírus. Parte dos governadores buscou promover políticas de isolamento social. Com isso, a questão da continuidade dos serviços públicos entrou, como prioridade, na pauta das discussões sobre possíveis soluções. Afinal, uma das características centrais dos serviços públicos diz respeito à continuidade. Nesse ponto de pauta, os processos de transformação digital ganharam maior destaque.

O conceito de transformação digital tem relação com o conceito SmartCities (ou cidades inteligentes), no qual, no decágono proposto, toda essa transformação se dá por meio das pessoas e para as pessoas. De nada adianta uma cidade construída nesses aspectos se o ponto central não for considerado nas políticas públicas. $\mathrm{O}$ cidadão é o centro de todo esse processo para que a colaboração para resolução de problema, a resolução de conveniência e a consideração pela diversidade sejam realmente relevantes. $\mathrm{O}$ capital é o cidadão e este deve ser atraído, cuidado e retido (CUNHA, 2016).

Nesse contexto, também podemos levar os processos de transformação digital com relevância inclusive para os negócios privados, pois, em um contexto de pandemia, o comércio eletrônico cresceu e o mesmo precisa de respaldo logístico para se desenvolver e se mostrar mais efetivo (EXAME, 2020). O gargalo se encontra na logística, principalmente na distribuição. É importante salientar que a participação do setor privado em comum acordo com o setor público é essencial para acelerar o desenvolvimento e a sustentabilidade dos projetos, trazendo conhecimentos, habilidades, recursos e a construção de 
novos modelos de negócio sustentáveis, numa parceria público-privada (CUNHA, 2016). É importante essa necessidade de transformação digital, principalmente para o contexto pós-pandêmico, que provavelmente deverá combinar atividades humanas presenciais e remotas.

A pandemia expõe diversas fragilidades brasileiras, inclusive as fragilidades e as vulnerabilidades que cresceram com a agenda das reformas liberais desde 2016: i) deterioração geral da qualidade dos serviços públicos; ii) informalidade laboral; e iii) desigualdades sociais (FARIA, TEIXEIRA e MEDEIROS, 2020). As medidas de austeridade fiscal reduziram recursos de programas sociais importantes para combater a pandemia, segundo o Instituto de Estudos Socioeconômicos (INESC, 2020). As medidas de austeridade fiscal e a aprovação da Emenda Constitucional n. 95, (BRASIL, 2016), conhecida como o teto de gastos, reduziram as políticas sociais necessárias para proteger a população mais vulnerável.

Há grandes dificuldades, quando não há impossibilidades lógicas, para se buscar fazer mais com menos recursos para uma população que cresceu e que demanda serviços públicos de melhor qualidade. Não se pode olvidar que a renda do trabalho estagnou e que a informalidade era muito alta antes da crise.

Buscando atender ao princípio constitucional da eficiência, a administração pública precisa ser criativa, voltada para o seu fim, e buscar, portanto, mobilizar ferramentas que possibilitem ganhos de escala, eficiência e produtividade. Nesse sentido, os processos de transformação digital se mostram relevantes.

Destacam-se, portanto, iniciativas de e-government (governo eletrônico), algo mais próximo hoje de um governo digital. $\mathrm{E}$, considerando $\mathrm{o}$ foco do governo eletrônico e do conceito de cidade inteligente na prestação de serviços e na otimização de processos, os termos se tornaram cada vez mais intrincados.

Temos, nesse contexto, Smart Government (governo inteligente). Podemos fazer as cidades inteligentes como um nó de uma rede urbana global. Estar nesse tipo de processo implica em maior transparência e dados abertos. Uma abordagem de estudo de caso permite apresentar instâncias específicas das práticas e políticas de governo eletrônico e de cidades inteligentes entrelaçadas e convergentes, com um objetivo exploratório (CUNHA, 2016; DENSCOMBE, 2017).

Assim, podemos definir um governo digital que busca ser mais inteligente do que uma administração tradicional. Deve buscar agilidade, eficiência e responsabilidade frente às demandas da cidadania. Há um foco maior em resultados, não apenas nos procedimentos burocráticos corretos. O Governo Eletrônico diz respeito à utilização das tecnologias de informação e comunicação (TICs), por parte dos entes públicos, para o atendimento de necessidades específicas dos cidadãos (MUSTAFA; IBRAHIM; MOHAMMED, 2020).

O Brasil já possui algumas atividades, nessa direção. Essas iniciativas têm sido muito bem vistas pela comunidade internacional. Desde 2014, por meio de um decreto presidencial, foi sendo estabelecida a Política Nacional de Participação Social e criado o Sistema Nacional de Participação Social (BRASIL, 2014), apesar de revogada pelo Decreto $n$. 9.759, de 2019 (BRASIL, 2019), o que demonstra um caminho contrário a esse processo. Essa política governamental, do decreto da Política Nacional de 2014, foi realizada por meio de ferramentas de Governo Eletrônico e já realizou mais de 200 processos participativos e um grande número de consultas públicas. Outra iniciativa de destaque, diz respeito à criação da política brasileira de dados 
abertos, instituída pelo Decreto n. 8.777, 2016 (BRASIL, 2016), que tem por objetivos: a promoção da transparência dos atos dos agentes públicos; a promoção da participação social; o desenvolvimento de novos e melhores serviços governamentais; e a promoção de atividades que apoiem o empreendedorismo.

Todas essas iniciativas só lograrão êxito se acompanhadas por esforços governamentais nos processos de inclusão digital. Não basta um processo de transformação digital, seja por meio dos conceitos de e-governement, smartgovernment ou smartcities, sem o elemento central, o cidadão, participante de toda essa transformação. Então, não há dúvidas de que o Brasil precisará de soluções que ofereçam caminhos para acesso a serviços públicos a uma parcela maior de sua população, pois o cenário que se desenha para o cenário pós-pandêmico é de grandes dificuldades para geração de emprego e renda.

\section{DISCUSSÕES SOBRE A DESGLOBALIZAÇÃO: LOGÍSTICA E CADEIAS DE SUPRIMENTOS}

As cadeias de suprimentos sofreram metamorfoses na virada da década de 1980 para os anos 1990. Segundo François Chesnais (1996), a mundialização do capital, algo que muitos chamam de globalização, reorientou e reorganizou processos produtivos de bens e serviços em diversas regiões. Empresas em rede, conhecidas como as cadeias globais de valor, foram organizadas pela lógica da acumulação financeira.

A desindustrialização de países e regiões prósperas esteve associada a esse processo, assim como a desindustrialização precoce de países periféricos, como é o caso brasileiro. A lógica das cadeias globais de valor apontava para um ajustamento global nas margens de lucro, demandando, portanto, "pressões para baixo" nos custos sociais de produção.
Processos legislativos do tipo "race to the bottom" se tornaram as normas reformistas em diversos países, pouco importando na prática as ideologias e os compromissos políticos assumidos em campanha. Não foi por acaso que as desigualdades sociais cresceram em muitos países, ainda que elas tenham caído na comparação entre países a partir da emergência da Ásia, principalmente da China (MILANOVIC, 2019). Essas desigualdades sociais tendem a crescer com a pandemia, pois houve a precarização dos mercados de trabalho em diversos países.

O gerenciamento da cadeia de suprimentos é um conceito mais amplo que o de logística. Segundo Christopher (2007, p. 4), esse gerenciamento busca "criar vínculos e coordenação entre os processos de outras organizações existentes no canal, isto é, fornecedores e clientes, e a própria organização". Seu foco concentra-se, essencialmente, na cooperação e confiança das empresas em rede. Nesse contexto, as empresas exitosas possuem combinações de vantagens de custo e valor. Economia de escala é importante inclusive no mundo pós-fordista, mais orientado para a demanda. Curvas de experiência também são relevantes para as organizações, pois produtividade e ganhos de eficiência são resultados de esforços contínuos e aprendizado organizacional. Esse ambiente de concorrência global entre redes, "cadeias de valor", está bem distante do constructo teórico e abstrato da concorrência perfeita, no qual não existem barreiras à entrada de firmas e tampouco importam os efeitos de escala produtiva.

Do ponto de vista das cadeias de suprimentos, o abastecimento de alimentos vem sendo objeto de avaliações em diversos países e regiões (MEDEIROS, 2020). A Organização das Nações Unidas para a Alimentação e a Agricultura (FAO, em inglês), por sua vez, esperava interrupções nas cadeias de suprimento de alimentos em diversos países e regiões do mundo em abril e maio. Guardadas as 
devidas proporções de impacto da pandemia, os preços nos supermercados disparam no Estado do Espírito Santo. Produtos importados ficaram mais caros por causa da desvalorização cambial do real. Os produtos nacionais também acompanharam o viés de alta. Para fabricar alguns produtos, há a necessidade de insumos importados. A metade do trigo consumido no Brasil é importada, por exemplo. Em alguns casos, produtos fabricados no Brasil, sem relação com o valor do dólar, estão até $50 \%$ mais caros do que antes da crise. Os índices divulgados pela Fundação Getúlio Vargas (FGV) no final de março, IGP-M e IPC, apontaram que alimentos e matérias-primas brutas se destacaram nos aumentos de preços. Índices do IBGE também apontaram nesse sentido para os alimentos, inclusive para a Grande Vitória.

Tendo em vista à preocupação com o bem-estar social, a coordenação institucional de esforços federativos precisa levar em conta os aspectos logísticos de abastecimento e de manutenção da renda das famílias. Afinal, já estamos enfrentando diversos tipos de problemas nas cadeias de suprimentos globais, algo que revela o grau de autonomia relativa dos países, e inclusive enfrentamos grandes desafios na logística doméstica de abastecimento de alimentos. $\mathrm{O}$ setor de transporte brasileiro é fragmentado, familiar e pouco digitalizado. Esse mesmo setor enfrenta as fortes quedas de demanda e faturamento na pandemia e revela pouco fôlego para sobrevier à crise a partir dos seus próprios esforços (CNT, 2020). Na crise, um processo de transformação digital na logística brasileira precisaria crescer com o comércio eletrônico para afastar riscos de desnecessários problemas de desabastecimento. Resta saber se há capacidade para tanto em um contexto de descoordenação federativa de esforços e planos.
Em um contexto de "economia de guerra", não é razoável contar apenas com os mercados e os sinais dos preços livres para dar respostas satisfatórias à população. Para Fiani (2011, p. 163), “a ideia de uma economia organizada apenas por meio de mercados - competitivos - é teoricamente difícil de sustentar".

Essa ideia diverge da realidade concreta das economias modernas e das formas reais de concorrência na economia global. O economista José Roberto Afonso, em entrevista, foi enfático ao defender que Brasil precisa estruturar logo uma economia de guerra durante a atual crise (MATTOSO E CARNEIRO, 2020). Por economia de guerra, Afonso compreende que as empresas devam mudar o enfoque de suas atividades para ajudar o país. Como exemplo prático, fabricantes de automóveis poderiam fazer ambulâncias e fabricantes de roupas, equipamentos para profissionais de saúde. A reconversão industrial, uma espécie de substituição forçada de importações para muitos países, se mostrou uma necessidade real, não mera sinalização de preços nos mercados no atual contexto de pandemia.

Uma boa dose de desglobalização de elos de atividades econômicas parece uma hipótese plausível para o contexto pós-crise (SERIC E WINKLER, 2020). Essa discussão já está presente na Europa e também nos Estados Unidos. O fato é que a pandemia está provocando reflexões em muitos países sobre a real necessidade de se ter reservas estratégicas nacionais de capacidades produtivas de bens e serviços essenciais.

Pelo jeito, teremos um novo normal após a crise, bem diferente do contexto pré-crise. Diversos processos de reconversão produtiva estão em curso em diversos países, devido à pandemia, e pode-se esperar que se mantenham, em alguma medida, após a crise. Há inclusive a expectativa de que algumas iniciativas de Indústria 4.0, automação e digitalização de processos produtivos de bens e serviços, 
basicamente, ajudem a aproximar geograficamente os elos das cadeias produtivas do seu mercado final, rompendo, ainda que parcialmente, com a lógica anterior de alongamento e aprofundamento das cadeias globais de valor. As cadeias de valor, não todas, provavelmente, deverão ser encurtadas.

Nesse complexo teatro de operações próximo ao de "economia de guerra", os governos buscam coordenar e dirigir esforços produtivos para $\mathrm{o}$ abastecimento doméstico de bens e serviços necessários à preservação da vida humana. Essa substituição forçada de importações se impõe como realidade e necessidade em um contexto pandêmico. $\mathrm{O}$ Brasil estava desacelerando antes de ser atingido pela pandemia e a sua alta taxa de trabalho informal deveria ter merecido uma atenção maior da parte dos governantes. No Brasil, infelizmente, faltam coordenação e liderança da parte do governo federal para acelerar iniciativas de reconversão industrial. Ainda que o processo de desindustrialização precoce prejudique iniciativas mais ousadas de reconversão produtiva, há, felizmente, relevantes iniciativas ocorrendo, inclusive uma sob a coordenação da Federação das Indústrias do Espírito Santo (Findes). Há capacidades produtivas industriais no Brasil para esforços de reconversão na atual crise. As maiores dificuldades parecem estar mesmo no plano da coordenação federativa de esforços e planos.

Não sabemos como será o futuro pós-pandêmico. Afinal, combinaremos atividades econômicas presenciais com atividades remotas e teremos que investir mais esforços em processos de transformação digital nas organizações? Provavelmente sim. Nesse sentido, é razoável supor que ocorrerão processos de redesenho profundo das organizações após a pandemia. $\mathrm{O}$ investimento público em infraestrutura também será relevante, de preferência com enfoque na sustentabilidade. Um "novo acordo verde" (Green New Deal, em inglês) seria muito interessante. Dessa proposta democrática surgida nos Estados Unidos, é possível destacar dois aspectos, pelos seus efeitos multiplicadores em termos de emprego e renda, para o Brasil: 1) reformar e consertar infraestruturas existentes para diminuir emissões e melhorar a eficiência energética; 2) fomentar indústrias "limpas", usando tecnologia para reduzir as emissões. A cooperação multilateral será importante para a economia mundial. Entretanto, não será possível evitar alguma dose de desglobalização de atividades econômicas em um contexto vindouro que demandará significativos estímulos fiscais e investimentos públicos.

Ainda que as incertezas prevaleçam na atual conjuntura, existem tensões diversas entre países e tendências de desglobalização de cadeias globais de valor. Esse assunto não tem sido tratado da forma que merece no Brasil, cujo governo federal tem se mostrado tímido para coordenar esforços domésticos de combate à pandemia. Persistem no governo a crença e a aposta na agenda de reformas liberais. Vários governos nacionais abandonaram o caminho das reformas liberais, inclusive a retórica liberal padrão, quando foram efetivamente forçados a enfrentar a grave crise vigente. Talvez seja muito cedo para afirmar categoricamente qual será o desfecho desse momento histórico. O importante é que o Brasil seja efetivamente capaz de preservar vidas humanas e aprender com a crise. Não será fácil a reconstrução nacional após a pandemia por conta dos efeitos de histerese no mercado de trabalho e nas capacidades produtivas instaladas.

\section{CONCLUSÕES}

Todos os países, ao longo de sua história, enfrentaram graves crises de várias formas, natureza e extensão. Sejam de saúde, sejam econômicas, as crises foram e serão sempre recorrentes. 
Recentemente, por exemplo, o Brasil enfrentou crises de energia elétrica (2001), crises por estiagem prolongada (em 20132014), crises em relação à dengue, zika, dentre outras. O que as distingue da crise atual, tanto para o caso brasileiro quanto para o de outros países, é que mesmo com o aprendizado acumulado, algumas situações são inéditas no enfrentamento do coronavírus.

O enfrentamento direto da problemática fez frear abruptamente a economia, tanto pelo lado da oferta como pelo da demanda. Isso levou a uma necessidade urgente de combinação entre a agenda política e a econômica, valendo-se de vários instrumentos econômicos e de gestão pública para ser capaz de enfrentar os desafios que rapidamente se desenharam.

Este artigo apresentou algumas proposições levantadas pelo Observatório do Desenvolvimento Capixaba (tanto econômicas quanto de gestão pública) para que o Brasil e o Espírito Santo possam passar por esse momento, reduzindo ou mitigando os efeitos da crise.

Embora a efetividade das medidas não possa ser garantida ex ante, vale dizer que elas sinalizam para elementos cruciais para a gestão da crise e para que as consequências da crise sejam mais amenas para os brasileiros e capixabas, já que renda e emprego serão as principais variáveis afetadas pela pandemia.

\section{REFERÊNCIAS}

BARBOSA FILHO, F. H. A crise econômica de 2014/2017. Estud. av. [online]. 2017, vol.31, n.89 [cited 202005-03], pp.51-60. Disponível em: $<\mathrm{http}: / /$ www.scielo.br/4014201700010001lng=en $\&$ nrm=iso $>$. Acesso em: $1^{\circ}$ maio 2020.

BRASIL. Decreto Presidencial. Decreto n. 8.243, de 26 de maio de 2014, pag.6, sessão 1 (Publicação original).
BRASIL, Decreto Presidencial. Decreto n. 8.777, de 11 de maio de 2016. Diário Oficial da União, sessão 1, de 12 mai 2016, pag. 21. Disponível em: $<$ http://pesquisa. in.gov.br/imprensa/jsp/visualiza/index.jsp? jornal $=1 \&$ data $=12 / 05 / 2016 \&$ pagina $=21$. Acesso em: 29 abr. 2020.

BRASIL. Constituição (1988). Emenda constitucional n. 95, de 15 de dezembro de 2016. Diário Oficial da União, Seção 1, 16 dez 2016, pag. 2. Disponível em: $<$ https://www.jusbrasil.com.br/diarios/133 607114/dou-secao-1-16-12-2016-pg-2>. Acesso em: 29 abr. 2020.

BRASIL. Decreto Presidencial. Decreto n. 9759, de 11 de abril de 2019. Diário Oficial da União, Sessão 1 - extra, 11 abr 2019. Edição 70-A, pag. 5. Publicado em: 11/04/2019 | Edição: 70-A | Seção: 1 Extra | Página: 5.

\section{CHESNAIS, F. A mundialização do} capital. São Paulo; Xamã, 1996.

\section{CHRISTOPHER, M. Logística e} gerenciamento da cadeia de suprimentos. 2.ed. São Paulo: Thomson Learning, 2007.

\section{CNT - CONFEDERAÇÃO NACIONAL} DO TRANSPORTE. Pesquisa de Impacto no Transporte Covid-19. Brasília (DF): CNT. Disponível em: $<$ https://www.cnt. org.br/painel-impacto-covid19>. Acesso em: 7 abr. 2020.

\section{CUNHA, M. A. Smartcities:} transformação digital de cidades. São Paulo: Programa Gestão Pública e Cidadania - PGPC, 2016.

\section{DATASUS. Banco de dados da} infraestrutura hospitalar. 2020. Disponível em: < https://datasus.saude. gov.br/informacoes-de-saude-tabnet/>. Acesso em: 30 abr. 2020. 
DENSCOMBE, $M$. The good research guide. NewYork, NY: Open University Press, 2017.

DIAS N. A. Déficit de acesso a coleta de esgoto sanitário o Espírito Santo.

Dissertação de Mestrado. Programa de Pós Graduação em Engenharia e

Desenvolvimento Sustentável. Ufes, 2018.

ES BRASIL. Obras paralisadas no

Estado podem ser "destravadas".

Disponível em: <https://esbrasil.com.br

/obras-paralisadas-estado/>. Acesso em: 04 mai 2020.

EXAME. Como o comércio eletrônico cresceu - e mudou - no meio da pandemia. Disponível em:

$<$ https://exame.abril.com.br/negocios/com o-o-comercio-eletronico-cresceu-e-mudouno-meio-da-pandemia/> . Acesso em: 28 abr. 2020 .

FARIA, L. H.; TEIXEIRA, R. B.; MEDEIROS, R. L. O Covid-19 e as possibilidades de reconversão produtiva. Disponível em: $<$ https://gemad.net/18categoria-pt-br/divulgacao-cientifica/74-ocovid-19-e-as-possibilidades-dereconversao-produtiva $>$. Acesso em: 28 abr. 2020 .

FIANI, R. Cooperação e conflito: instituições e desenvolvimento econômico. Rio de janeiro: Elsevier, 2011.

FUNDAÇÃO GETÍTULO VARGAS FGV /IBRE. Desigualdade da renda do Trabalho no Brasil. 2019. Disponível em: $<$ ww.portalfgv.com.br>. Acesso em: 30 abr. 2020.

FUNDAÇÃO GETÍTULO VARGAS FGV /IBRE. Sondagens de Confiança. 2020. Disponível em: $<$ https://portalibre.fgv.br/estudos-epesquisas/sondagens-e-indices-deconfianca/>. Acesso em: 30 abr. 2020.
FUNDAÇÃO GETÍTULO VARGAS FGV /IBRE. Carta do IBRE. 2020a. Disponível em: $<$ https://portalibre.fgv.br/ $>$. Acesso em: 30 abr. 2020.

FURTADO, C. Brasil: a construção interrompida. Rio de Janeiro. Paz e Terra: 1992.

GALA, P; ZAGATO, L; PINHEIRO, F; HARTMANN, D. A armadilha da renda média e os obstáculos à transformação estrutural: a curva $\mathrm{S}$ da complexidade econômica. Working Paper, FGV 508. São Paulo: FGV, 2019.

\section{INESC - INSTITUTO DE ESTUDOS SOCIOECONÔMICOS. O Brasil com} baixa imunidade - Balanço do Orçamento Geral da União 2019. Disponível em: $<$ https://www.inesc.org.br/obrasilcombaixa imunidade/>. Acesso em: 28 abr. 2020.

INSTITUTO DE DESENVOLVIMENTO INDUSTRIAL E EDUCACIONAL DO ESPÍRITO SANTO (Ideies). Boletim de Economia Capixaba. Disponível em: $<$ http://portalideies.centralus.cloudapp.azur e.com/system/repositories/files/000/000/58 1/original/Boletim-Abril_2020.pdf? 15882 78 387. Ano 4, no 32, ISSN - 2595-9247. Abril de 2020>. Acesso em: 03 maio 2020.

INSTITUTO BRASILEIRO DE GEOGRAFIA E ESTATÍSTICA - IBGE. Contas Nacionais 2020. Disponível em: $<$ https://www.ibge.gov.br/estatisticas/econ omicas/contas-nacionais.html>. Acesso em: 30 abr. 2020.

INSTITUTO BRASILEIRO DE GEOGRAFIA E ESTATÍSTICA - IBGE. Pnad Contínua Brasil. 2020a. Disponível em: <https://www.sidra.ibge.gov.br $>$. Acesso em: 30 abr. 2020.

INSTITUTO BRASILEIRO DE GEOGRAFIA E ESTATÍSTICA - IBGE. Pnad Contínua - Espírito Santo. 2020 b. Disponível em: $<$ https://www.sidra. ibge.gov.br> . Acesso em: 30 abr. 2020 . 
INSTITUTO JONES DOS SANTOS NEVES-IJSN. Panorama econômico Espírito Santo IV Trimestre 2019. 2020. Disponível em: $<$ http://www.ijsn.es.gov.br /component/attachments/download/6877>. Acesso em: $1^{\circ}$ maio 2020.

\section{INSTITUTO JONES DOS SANTOS} NEVES. Perfil da Pobreza no Espírito Santo: Famílias Inscritas no CADÚNICO (2019a). Disponível em: <http://www. ijsn.es.gov.br/component/attachments/dow nload/6702>. Acesso em: 02 abr. 2020.

INSTITUTO DE PESQUISAS ECONÔMICAS APLICADAS - IPEA.

Carta de Conjuntura. Abril 2020. 2020. Disponível em: <www.ipea.gov.br>. Acesso em: $1^{\circ}$ maio 2020.

MATTOSO, C.; CARNEIRO, M. Brasil tem que estruturar economia de guerra durante crise do coronavírus, defende economista. Disponível em: <https:// www1.folha.uol.com.br/mercado/2020/04/ brasil-tem-que-estruturar-economia-deguerra-durante-crise-do-coronavirusdefende-economista . $\operatorname{sh}$ tml?origin $=$ folha $>$. Acesso em: 28 abr. 2020.

MEDEIROS, R. Cadeias de suprimentos na pandemia de Covid-19. Disponível em: $<$ http://desenvolvimentocapixaba.net /publicacoes/artigos-de-opiniao/72cadeias-de-suprimentos-na-pandemia-decovid-19>. Acesso em: 28 abr. 2020.

MILANOVIC. B. Capitalism, alone - the future of the system that rules the world. Cambridge (MA): Harvard University Press, 2019.

MIOTTO, R.; PAIXÃO, A. Dados de localização de celulares mostram redução no isolamento social no Brasil pela $2^{\text {a }}$ semana seguida. Disponível em: $<$ https://g1.globo.com/economia/tecnologi a/noticia/2020/04/17/dados-de-localizacaode-celulares-mostram-reducao-noisolamento-social-no-brasil-pela-2a- semana-seguida.ghtml $>$. Acesso em: 28 abr. 2020 .

MUSTAFA, A.; IBRAHIM, O.; MOHAMMED, F. E-Government Adoption: A Systematic Review in the Context of Developing Nations. International Journal of Innovation, v. 8, n. 1, p. 59-76, 2020. Disponível em: $<$ http://www.spell.org.br/documentos/ver/5 6580/e-government-adoption--asystematic-review-in-the-context-ofdeveloping-nations $>$. Acesso em: 02 maio 2020.

SEDES. Secretaria de Estado de Desenvolvimento. Medidas econômicas para manutenção de empregos durante enfrentamento à Covid-19. Disponível em: $<$ https://sedes.es.gov.br/>. Acesso em: 28 abr. 2020.

SEDURB - Secretaria Estadual de Saneamento Habitação e Desenvolvimento Urbano. Plano Estadual de Habitação. Vitória Sedurb, 2014.

\section{SERIC, A.; WINKLER, D. Managing} COVID-19: Could the coronavirus spur automation and reverse globalization? Disponível em: $<$ https://iap.unido. org/articles/managing-covid-19-couldcoronavirus-spur-automation-and-reverseglobalization>. Acesso em: 28 abr. 2020.

SESA - Secretaria de Estado da Saúde. iNova Saúde: uma revolução na saúde do capixaba. 2019. Disponível em: $<$ https:// saude.es.gov.br/Not $\% \mathrm{C} 3 \%$ ADcia/inovasaude-uma-revolucao-na-saude-docapixaba>. Acesso em: 03 maio 2020. 